\title{
Bavarian universities set to gain autonomy
}

[MUNICH] Universities in Bavaria, Germany's largest state, will become the first in Germany to have explicit mechanisms for ensuring research excellence, competition for grants and budget autonomy, following the approval last month of a radical new university law.

Under the law, universities will in future be able to appoint professors, distribute their own budgets and open or close faculties without reference to the science ministry. They will also be able to introduce degrees directly equivalent to bachelors' and masters' degrees.

Bavaria's 10 universities will also have to compete for the first time for their share of the state budget for higher education. They will be judged not just on student numbers but also on research criteria, such as numbers of graduate students and the amount of external grant money received.

The monitoring role of the Bavarian ministry of education, science and culture will be taken over by an external advisory university board, known as the Hochschulrat. Each university will have its own Hochschulrat, consisting of three representatives from local industry and two independent academics whose appointments will require the approval of the science minister. It will have advisory powers only.

The creation of Hochschulräte has been

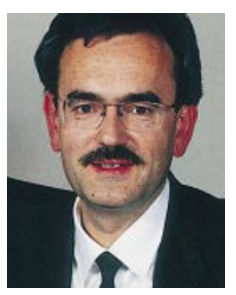

the most controversial aspect of the new law. The University of Basel in Switzerland became the first German-speaking university to introduce such a board in 1996: its board has full decisionHerrmann: wanted making power. At least stronger boards. from an administrative point of view, the Basel model is regarded as a success; for example, the average time to appoint a professor has been reduced from two years to six months.

But there has not yet been a significant increase in the value of grants from industry. "Increasing the share of outside financing, which was 10 per cent or so of the total university budget in 1996, has top priority in the coming years," says Beat Münch, spokesman for the University of Basel.

The Bavarian Hochschulräte will not have decision-making powers. But they have still proved unpopular with those who fear that the heavy presence of industrialists will push universities too far towards applicationsoriented research. Also, smaller universities fear that the best industrial representatives will serve on the boards of the big universities based in Munich, the Bavarian capital, and that they will be left with the second best.

But others are enthusiastic, although
Wolfgang Herrmann, president of Munich's Technical University - the most important university for science in Bavaria - says he would have preferred a board with decisionmaking powers, rather than one with only advisory and monitoring functions.

The Bavarian parliament is expected to give rapid approval to the bill and the boards will have to be in place by autumn next year. Other Länder in Germany have been discussing reform of their own university laws, but so far with little success. Although Länder hold full responsibility for universities, they have to work within a federal 'framework' law, intended to guarantee equal value to all academic degrees, regardless of the university awarding them.

Reform of this framework law is under way to allow competition between universities, which are creaking under the strain of student numbers - all students with a highschool leaving certificate have the right to a university education. But this would simultaneously destroy the concept of equivalence of degrees, which is one of the main reasons the long-discussed changes have still not been approved (see Nature 388, 820; 1997).

Meanwhile, Bavaria's conservative science minister, Hans Zehetmair, is pleased his extensive reform plans have been put into practice. "It was a balancing act, but we made it in the end," he says.

QuirinSchiermeier

\section{Lower budget deficit offers hope of research bonus in Canada}

[MONTREAL] Canadian researchers are queuing to claim their share of a fiscal dividend which the Finance Minister, Paul Martin, expects from lowering the federal budget deficit.

Separate presentations to the Parliamentary Standing Committee on Finance have called for a doubling of the Medical Research Council (MRC) budget, a 60 per cent increase in Social Sciences and Humanities Research Council (SSHRC) funds, and a 50 per cent increase in the budget of the Natural Sciences and Engineering Research Council (NSERC).

Also, the Council for Health Research in Canada, a group of voluntary health agencies and research institutions, is aiming to alert government and the public to "Canada's weak investment in health research (which) contrasts sharply with the trends and priority given to research in several other G-7 countries".

Some scientists are optimistic of success, as Martin has said that half of any surplus would go to social spending and has also spoken positively about science, technology and innovation. But the government may not provide money in the councils' annual budgets, as that would lock it into more or less permanent expenditure. The outcome will not be known for at least a month.

The Council for Health Research in Canada says expenditure on health research has fallen by about 10 per cent since 1990; US spending has risen more than 80 per cent in the same period. Canada's MRC allocates only C \$7.27 (US\$5.2) per capita for 1998, whereas the US National Institutes of Health allocate C\$49.8 per capita. The council recommends minimum increases in MRC's base budget of C\$60 million for each of the next four years, resulting in a doubling by 2002 .

A submission by the Association of Universities and Colleges of Canada, the Canadian Association of University Teachers, the Canadian Consortium for Research, the Humanities and Social Sciences Federation of Canada and the Canadian Graduate Council recommends an increase of 50 per cent in federal funds for the granting councils over four years.

Last year, the government committed C\$800 million to a Canada Foundation for Innovation. The submission says that, with funding for this beginning in 1998,

"investments in the granting councils in subsequent years will be critically important if we are to take advantage of the enhanced research capacity".

The submission also calls as an "utmost priority" for 20 per cent of new granting council funds to be allocated to promote research careers. Thomas A. Brzustowski, president of NSERC, elaborated on this in asking for large increases in research subsidies totalling C\$160 million.

Brzustowski said the key to success in the knowledge-based economy was to prepare young people to match the world best in science and engineering, but this is not happening. Support for postgraduate students by NSERC, for example, has not changed significantly for five years.

The result is that many fail to develop to their full potential or go abroad, where they receive much higher levels of support. Brzustowski says that an increase of at least 25 per cent is needed in both the value and number of postgraduate scholarships.

He also called for a fourfold extension of NSERC's Undergraduate Student Research Awards in laboratories across Canada, and a 25 per cent increase in graduate and postdoctoral stipends. 